\title{
EFFECT OF GOSERELIN AND LEUPROLIDE ADDED TO THE SEMEN ON REPRODUCTIVE PERFORMANCE IN RABBITS - SHORT COMMUNICATION
}

\author{
Piotr GOGOL ${ }^{*}$ \\ Department of Biotechnology of Animal Reproduction, National Research Institute of \\ Animal Production, Krakowska 1, 32-083 Balice/Kraków, Poland
}

(Received 16 June 2015; accepted 28 October 2015)

\begin{abstract}
The aim of this study was to evaluate the ability of two synthetic GnRH analogues, goserelin and leuprolide, to induce ovulation in rabbit does using intravaginal administration. A total of 252 primiparous lactating does were randomly divided into five groups that, at the time of insemination, received the following treatments for ovulation induction: $1 \mu \mathrm{g}$ of buserelin administered intramuscularly (control group), $5 \mu \mathrm{g}$ of goserelin added to the semen dose (Group G5), $10 \mu \mathrm{g}$ of goserelin added to the semen dose (Group G10), $5 \mu \mathrm{g}$ of leuprolide added to the semen dose (Group L5), and $10 \mu \mathrm{g}$ of leuprolide added to the semen dose (Group L10). The kindling rate was $80.5 \%$ in Group G10 and $75.0 \%$ in Group L10; these values are comparable to the kindling rate obtained in the control group (85.9\%). The kindling rates in Groups G5 and L5 were significantly lower than in the control group $(60.0 \%, 54.2 \%$ and $85.9 \%$, respectively). The number of live-born rabbits was not significantly affected by the ovulation induction treatment. As regards the total number of rabbits born the only significant difference was observed between Groups G5 and L5. This study shows the possibility of inducing ovulation in rabbits by adding goserelin and leuprolide directly to the semen dose.
\end{abstract}

Key words: Rabbit, ovulation induction, GnRH analogue, insemination

The use of artificial insemination (AI) in rabbits has become a routine practice in European farms. Because the physiology of reproduction in the rabbit doe is characterised by induced ovulation when using AI, ovulation has to be induced by artificial methods. The most frequent method used for ovulation induction in rabbits is the intramuscular administration of GnRH or its synthetic analogues. Different GnRH analogues (gonadorelin, buserelin, triptorelin, lecirelin) have been used successfully, and the standard insemination technique includes an intramuscular injection at different dosages depending on the efficiency of the GnRH analogue (Rebollar et al., 1997). The most frequently used analogue is buserelin (Quintela et al., 2004).

*E-mail: pgogol@izoo.krakow.pl; Phone: 0048 (666) 081-282; Fax: 0048 (122) 855-162 
In order to improve insemination practices, individual ovulation induction by subcutaneous or intramuscular treatment with a GnRH analogue solution could be substituted by mucosal absorption after supplementation of the semen extender with a GnRH analogue. This kind of application of the hormone simplifies the AI procedure. Previous studies have shown that the GnRH analogue buserelin can be administered intravaginally by adding the hormone to the semen dose, with similar results to those obtained by intramuscular injection (Quintela et al., 2004; Viudes-de-Castro et al., 2007; Vicente et al., 2008). However, it was found that, in order to ensure fertility rates comparable with those obtained with the usual intramuscular injection, the intravaginal buserelin dose had to be at least 15-fold higher (Quintela et al., 2004).

Several authors have recently described the addition of different GnRH analogues directly to the semen dose (Viudes-de-Castro et al., 2007; Vicente et al., 2008; Quintela et al., 2009; Rebollar et al., 2012; Gogol et al., 2014). Before a routine application of this method of ovulation induction on rabbit farms it is necessary to find more potent analogues. The aim of this study was to evaluate the ability of two synthetic GnRH analogues, goserelin and leuprolide, to induce ovulation in rabbit does using intravaginal administration.

A total of 252 primiparous lactating commercial hybrid does were used in this study. The rabbits were housed in individual cages with an artificial lighting programme of $10 \mathrm{~h} \mathrm{light} / 14 \mathrm{~h}$ dark, which was changed to $16 \mathrm{~h} \mathrm{light} / 8 \mathrm{~h}$ dark 8 days before insemination. The does were fed a commercial diet ad libitum and drinking water was also available ad libitum. The bucks used in this study were housed in individual cages with water provided ad libitum, whereas feed was restricted to $180 \mathrm{~g} /$ day. Semen was collected using an artificial vagina, evaluated for sperm motility and concentration, diluted with the commercial extender Galap (IMV Technologies, France) to a concentration of $50 \times 10^{6}$ spermatozoa $/ \mathrm{ml}$, and stored at $17{ }^{\circ} \mathrm{C}$ for $3 \mathrm{~h}$. Sperm motility was assessed subjectively using a microscope equipped with a $10 \times$ negative phase contrast objective and a heated plate at $37^{\circ} \mathrm{C}$. Sperm concentration was determined with a haemocytometer using a Buerker counting chamber. Ejaculates with a volume higher than $0.4 \mathrm{ml}$ and sperm motility higher than $70 \%$ were pooled and used for insemination.

Does were inseminated using disposable plastic pipettes, and received a dose of $25 \times 10^{6}$ spermatozoa in a volume of $0.5 \mathrm{ml}$. All the does were inseminated on day 14 after parturition and were suckling 10 kits. To synchronise oestrus a 24-h mother-litter separation was applied. Females were randomly divided into five groups and submitted to different treatments for ovulation induction: (1) control group: $1 \mu \mathrm{g}$ /doe of buserelin acetate (Receptal, Hoechst A.G., Germany) administered intramuscularly immediately after the insemination; (2) Group G5: $5 \mu \mathrm{g} /$ doe of goserelin acetate (Sigma-Aldrich, St. Louis, MO, USA) administered intravaginally by addition to the semen dose; (3) Group G10: $10 \mu \mathrm{g} / \mathrm{doe}$ of goserelin acetate administered intravaginally by addition to the semen dose; 
(4) Group L5: $5 \mu \mathrm{g} /$ doe of leuprolide acetate (Sigma-Aldrich, St. Louis, MO, USA) administered intravaginally by addition to the semen dose; (5) Group L10: $10 \mu \mathrm{g} / \mathrm{doe}$ of leuprolide acetate administered intravaginally by addition to the semen dose.

At parturition, the total number of kits born and the number of kits born alive per litter were recorded for subsequent analysis.

A chi-square test was carried out to analyse the effect of treatment on the kindling rate. The effect of treatment on the number of kits born was analysed using the GLM procedure of Statistica 7 software. Means were compared using $t$-test and differences were considered significant at $\mathrm{P}<0.05$.

Kindling rates achieved with $10 \mu \mathrm{g}$ of goserelin and $10 \mu \mathrm{g}$ of leuprolide added to the semen dose were comparable to those obtained by the conventional insemination technique where ovulation is induced intramuscularly with $1 \mu \mathrm{g}$ of buserelin (Table 1). The kindling rates in groups stimulated with $5 \mu \mathrm{g}$ of goserelin and $5 \mu \mathrm{g}$ of leuprolide added to the semen dose were significantly lower than those recorded in the control group $(60.0 \%, 54.2 \%$ and $85.9 \%$, respectively). The number of live-born rabbits was not significantly affected by the ovulation induction treatment. In the number of total rabbits born the only significant difference was observed between Groups G5 and L5.

\section{Table 1}

Fertility and prolificacy of rabbit does submitted to insemination using different ovulationinduction treatments (mean \pm SEM)

\begin{tabular}{lcccc}
\hline Group & No. of does & Kindling rate (\%) & Live-born kits (n) & $\begin{array}{c}\text { Total number of kits born } \\
(\mathrm{n})\end{array}$ \\
\hline Control & 64 & $85.9^{\mathrm{a}}$ & $10.5 \pm 0.32$ & $11.0 \pm 0.31$ \\
G5 & 45 & $60.0^{\mathrm{bc}}$ & $11.1 \pm 0.36$ & $11.7 \pm 0.36^{\mathrm{a}}$ \\
G10 & 47 & $80.9^{\mathrm{a}}$ & $10.6 \pm 0.53$ & $10.9 \pm 0.54$ \\
L5 & 48 & $54.2^{\mathrm{b}}$ & $10.3 \pm 0.54$ & $10.7 \pm 0.45^{\mathrm{b}}$ \\
L10 & 48 & $75.0^{\mathrm{ac}}$ & $10.7 \pm 0.37$ & $10.9 \pm 0.40$ \\
\hline
\end{tabular}

Values marked with different superscript letters $(a, b, c)$ in the same column are significantly different $(\mathrm{P}<0.05)$. Control: $1 \mu \mathrm{g}$ of buserelin injected intramuscularly; G5: $5 \mu \mathrm{g}$ of goserelin added to the semen dose; G10: $10 \mu \mathrm{g}$ of goserelin added to the semen dose; L5: $5 \mu \mathrm{g}$ of leuprolide added to the semen dose; L10: $10 \mu \mathrm{g}$ of leuprolide added to the semen dose

The results of this study show the possibility of inducing ovulation in rabbits by adding the synthetic GnRH analogues goserelin and leuprolide directly to the semen doses. The doses of analogues $(10 \mu \mathrm{g}$ per doe) used in the present study were high enough to get results comparable to those obtained with the usual intramuscular treatment. 


\section{References}

Gogol, P., Trzcińska, M. and Bryła, M. (2014): Motility, mitochondrial membrane potential and ATP content of rabbit spermatozoa stored in extender supplemented with GnRH analogue [des-Gly10, D-Ala6]-LH-RH ethylamide. Pol. J. Vet. Sci. 17, 571-575.

Quintela, L. A., Peña, A. I., Vega, M. D., Gullón, J., Prieto, C., Barrio, M., Becerra, J. J. and Herradón, P. G. (2009): Reproductive performance of rabbit does artificially inseminated via intravaginal administration of [des-Gly 10, D-Ala6]-LHRH ethylamide as ovulation inductor. Reprod. Domest. Anim. 44, 829-833.

Quintela, L. A., Peña, A. I., Vega, M. D., Gullón, J., Prieto, M. C., Barrio, M., Becerra, J. J., Maseda, F. and Herradón, P. G. (2004): Ovulation induction in rabbit does submitted to artificial insemination by adding buserelin to the seminal dose. Reprod. Nutr. Dev. 44, 1-10.

Rebollar, P. G., Alvariño, J. M. R., Illera, J. C. and Silván, G. (1997): Effect of gonadoreline and naloxone on induction of ovulation and plasma LH in rabbit. J. Physiol. Biochem. 53, 205-210.

Rebollar, P. G., Dal Bosco, A., Millán, P., Cardinali, R., Brecchia, G., Sylla, L., Lorenzo, P. L. and Castellini, C. (2012): Ovulating induction methods in rabbit does: the pituitary and ovarian responses. Theriogenology 15, 292-298.

Vicente, J. S., Lavara, R., Lavara, F., Marco-Jimenez, F. and Viudes-de-Castro, M. P. (2008): Rabbit reproductive performance after insemination with buserelin acetate extender. Livest. Sci. 115, 153-157.

Viudes-de-Castro, M. P., Lavara, R., Marco-Jimenez, F., Cortell, C. and Vicente, J. S. (2007): Ovulation induced by mucosa vaginal absorption of buserelin and triptorelin in rabbit. Theriogenology 68, 1031-1036. 